\title{
AN ALTERATIVE PLACEMENT MODEL FOR NURSING STUDENTS: DISCOVERING NEW HORIZONS
}

\section{Key words}

Placement models

Traditional placements

Student Nurses

Supervision and assessment

Mentor

Practice Assessor

\section{Abstract}

This paper will explore the use of an alternative placement model and establish how it can be used in conjunction with the Nursing and Midwifery Council (NMC) standards for education and training (2018). Traditionally in nurse education, students were supported on a one to one basis by a qualified nurse mentor in placement. This could be a very intense relationship and could limit placement learning as students were only allocated to areas that have a qualified nurse mentor, exacerbating competing demands on placement capacity to support students. A Higher Education Institute (HEI) trialled an alternative placement model that utilised several healthcare related services traditionally not used for nursing placements. Some of these placements were allocated by the HEI, however students were also responsible for securing a number for themselves. The students were supported with their learning by appropriate healthcare staff in practice but were assessed by academic members of staff at the HEI acting as practice assessors. The project was 
evaluated positively overall by both students and staff. Students found it to be an empowering experience, which encouraged autonomous practice.

\section{Introduction}

The NMC stipulates that nurses gain the knowledge and skills necessary to enter the appropriate professional register via a split between theory and practice (NMC standards, 2010 \& 2018) on their undergraduate programme. The traditional model for placement for many Higher Education Institutions (HEIs) is for students to complete block placements in a designated placement area for a planned number of weeks at stages throughout each academic year of the programme. Previously during each traditional placement, the student undertook learning activities to meet course competencies under the supervision and assessment of a designated mentor. However, there has been growing awareness that this model can limit placement learning due to lack of mentor availability required for the traditional 1:1 approach. It also may not reflect recommendations for the future nurse (Willis, 2015) and the requirements of NMC standards (NMC, 2018) where leadership and inter-professional working is paramount. There are specific challenges currently experienced by HEl's to ensure that there is access to a diverse range of placement areas for all nursing students to gain skills that they may not see on their traditional placements such as hospital wards and community nursing teams (Millington et al 2019). This pressure is compounded by the competing demands on placement capacity given the range of learners in the workplace (Merrifield, 2015; Rylance et al, 2017) which also effects the availability for the supervision and assessment of students. Another key consideration is the need to develop a registered nurse with the resilience to practice effectively in contemporary healthcare (Thomas and Asselin, 2018). Therefore a variety of placement models can have benefits such as better awareness of other professional roles, increased placement capacity; 
increased skills for the established workforce; students enabled to work with specialist and emerging fields of practice and students better prepared for registration (O'Leary and Bromley 2009; McClimens et al 2013; Harrison-White \& King, 2015). Whilst Role Emerging Placements have grown in popularity for allied healthcare students (Dancza et al 2019) this is a novel approach to nurse education. An alternative placement experience was designed at one $\mathrm{HEI}$ to resolve some of the challenges identified above. This paper will outline the design of a new alternative placement, which explores previously untapped placement learning terrain.

\section{Alternative placement structure}

The alternative placement focused on public health and contextualising the services that were available to support healthcare (Ball, 2017), During the placement students accessed a range of health and social care services based in the NHS, private and voluntary sector to understand the interface between these organisations and the wider client journey. The placement experience also sought to make use of services that are relevant to the adult nursing curriculum, but could not mentor students in the traditional way under the NMC (2008) standards.

Students were given information on this bespoke placement structure during an orientation day and received a practice handbook. Progress was reviewed regularly during planned sessions with practice assessors from the $\mathrm{HEI}$ and recorded in the online practice assessment learning tool meaning that the practice assessors had ready access and contemporary awareness of student activity. A cohort of 30 nursing students in their second year were offered the two week alternative placement that consisted of completion of short placement experiences in areas such as serious incident review meetings, specialist nurse sites, and community mental health team and homelessness services (refer to figure 
1). A proportion of these experiences were allocated by the university and a similar proportion identified by students. In addition, students explored further related services and included activities such as review of relevant Care Quality Commission documentation and observation at Alcoholics Anonymous meetings. Resources were made available to enable the students to identify relevant learning opportunities.

Fig 1: Example of alternative placement experience:

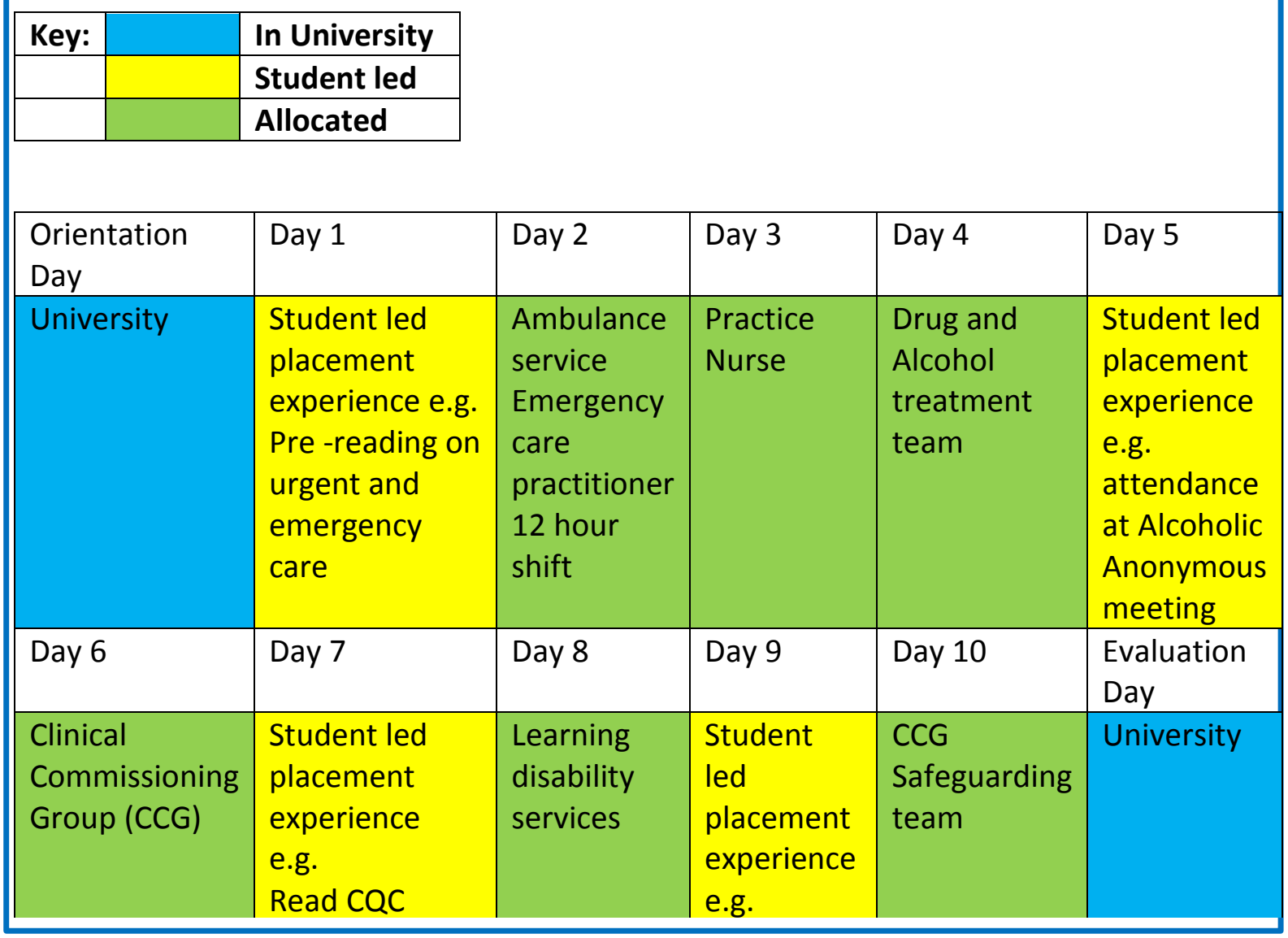

The student collected evidence in the form of reflective accounts and a short feedback document completed by the placement provider to inform the assessment process. Review and assessment occurred at the end of the placement during a one to one meeting between student and practice assessor from the HEI. The experience of assessing and making a judgement on the performance of the student required clear consideration, but was 
possible using clear documentation from personnel in the placement areas and evidence collated by the learner.

The existence of the online practice assessment tool enabled the practice assessor and student to remain in contact and 'feel connected' with one another without constant face to face contact. The practice assessor committed to regular reviews of the assessment tool, giving feedback and encouragement via the online format. This proved effective for most students but did challenge those who were not as proactive, in managing their learning with some students reporting that the self-directed elements were stressful. This was also identified previously by Clarke et al (2014) whilst supporting occupational therapy students. Using the online format enabled the practice assessor to identify struggling students at an early stage and offer the appropriate support. This long arm supervision was also found to be effective in a qualitative study by Kyte et al (2018) Endorsement of the assessment was undertaken by a second practice assessor in accordance with local HEI regulations. This is depicted in Fig 2 below. 


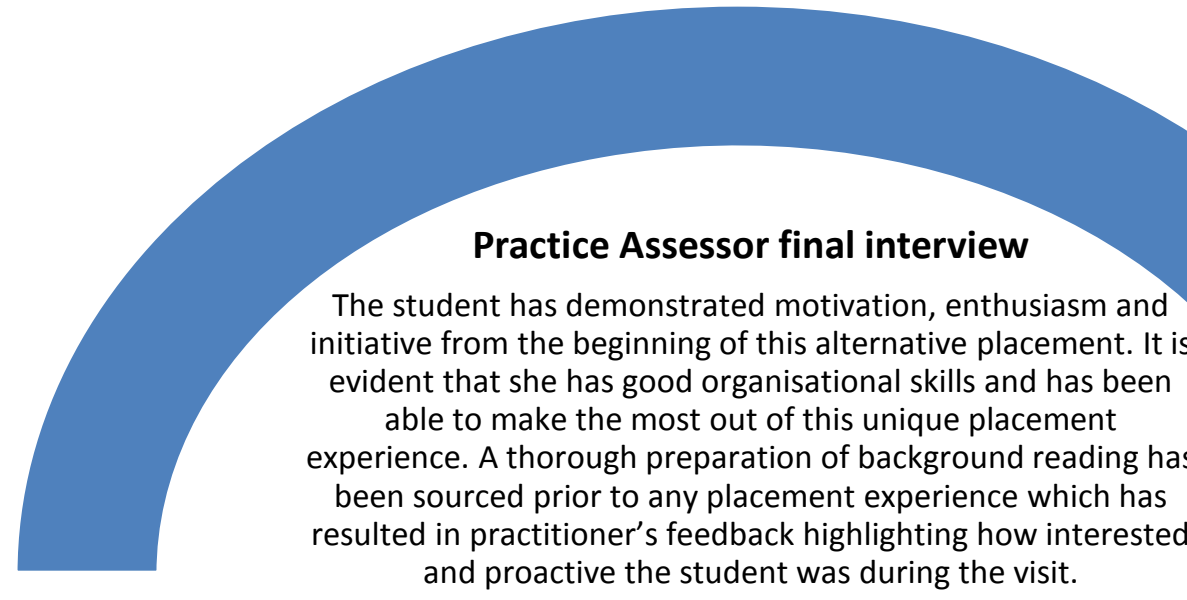

Learning opportunities have been utilised to the maximum and the student has been able to demonstrate how she will apply this new knowledge to future practice.

The student also was able to demonstrate an understanding of a concern raised in one practice area, how it was managed and future learning she will take from this episode.

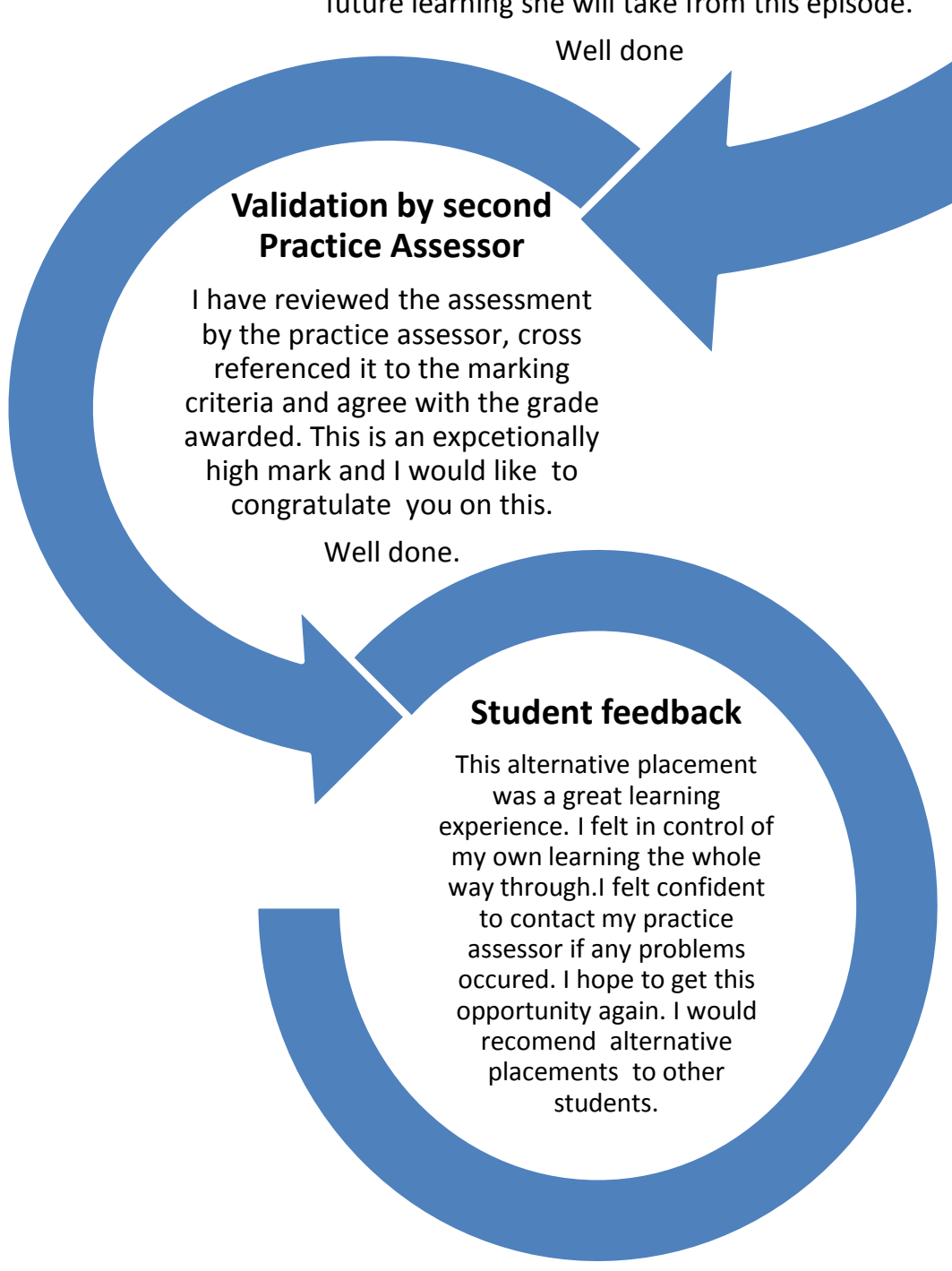




\section{Placement Evaluation}

The students were invited to attend a placement review and given the opportunity to complete a formal placement evaluation. The majority of students evaluated the placement very highly, viewing it as a unique learning experience (see Fig 3 and Fig 4).

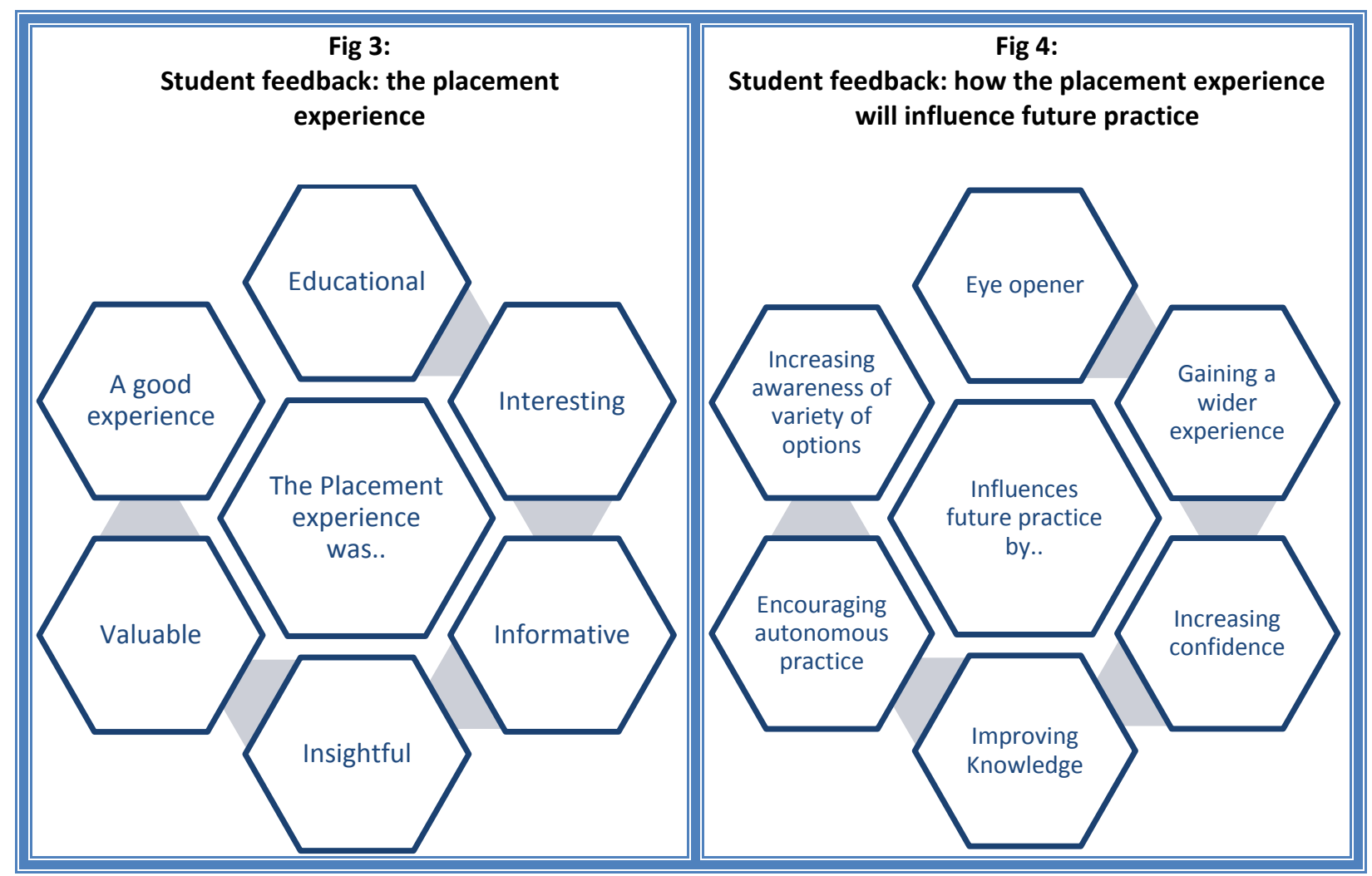

This positivity was also endorsed by the organisations and their staff who expressed via email correspondence and telephone conversations that they felt valued, and welcomed the opportunity to share and promote the valuable work occurring in their services. They also enjoyed having the students finding it a positive experience.

Some challenges were also highlighted which linked to the responsibility of the student organising their own placements, departure from the traditional placement model and anxiety that they would not obtain required clinical skills. 


\section{Discussion}

The student evaluation from the alternative placement demonstrates that this is a valuable placement experience.

While some students outlined difficulty adjusting to this placement format, the focus on student led placement activity and their responsibility in this has connotations for registered practice and is therefore seen as a positive. It also has links to other emerging placement models that emphasise the student's role more overtly than the traditional placement (Millington et al 2019). As a consequence of our experience using the alternative placement model, four themes emerged.

\section{$\underline{\text { Accessing non-traditional learning environments }}$}

The benefit of students accessing services that they may not routinely consider engaging with was seen as a beneficial learning experience. This also assisted with effective use of traditional placements while enabling good use of areas that may not be in a position to offer the traditional placement, often because they may not have had a qualified mentor present.

\section{Supervision and Assessment in Practice}

A key learning point was to ensure that assessors were confident in their assessment of students and that students felt 'connected' to their practice assessor at the HEI. This was facilitated through the traditional start, middle and end interviews.

The assessment relied upon the evidence and feedback gathered by the student. This was a surprisingly easy departure from traditional assessment of practice by one mentor who 
makes the assessment decision. Practice Assessors based in the HEI reported during the evaluation process that they had sufficient evidence to undertake a robust assessment despite minimal contact with the student.

\section{Supporting students to develop leadership and resilience}

The alternative placement model enabled students to identify some placement activities independently as part of their overall placement. While this can be likened to spoke placements that may occur within a traditional placement, students were expected to consider their practice learning needs and identify placement experiences accordingly. For some students this presented them with the opportunity to explore areas of professional interest that would be of use when back on placement in more traditional services. The placement experience was agreed with their practice assessor and learning outcomes were articulated by the student. This led to positive evaluations with some students expressing how their insight into the everyday life of people they would be caring for in a traditional placement had increased. However, some students struggled with the opportunity to identify placement experiences for themselves. This group of struggling students required a higher level of direction from their practice assessor and at times overt signposting to placement opportunities. The practice assessor team from the HEI supported these students, using a coaching style to encourage students to understand how they could use this opportunity for practice learning. However, the ability for all students to be independent learners will need consideration for future placements where long-arm assessment occurs, possibly with increased focus upon independent learning and coaching. However, the majority of students found the overall experience positive. One student who particularly embraced the alternative placement commented: 
"I have always found the concept of student led learning challenging on usual placements but this experience embodies the approach fully".

The opportunities for learners to lead on some facets of their placement learning links to the responsibilities of a registered practitioner and should be seen as part of the positive rationale for this placement model. The key will be to assist students to understand this through consistent preparation.

\section{Preparation of staff supervising and assessing students at the HEI}

The practice assessors were prepared by being orientated to the placement structure and their responsibilities as practice assessors. The use of coaching as opposed to traditional mentoring was intrinsic in the preparation and was a pivotal facet. There was a designated placement lead to assist with queries and maintain parity for the placement experiences who was accessible to practice assessors during the placement.

\section{Conclusion}

The alternative placement model enabled the HEI to successfully utilise hitherto unused placements. This was evaluated positively by the students and practice partners. It was found to be a valuable informative experience which encouraged autonomous practice, thereby supporting the NMC (2018) requirements for students to be empowered and independent. The experience has enabled the HEI to understand how they can support innovative and effective placement learning, which can only be a positive in light of the challenges for placement capacity for an emerging range of learners. The placement model is not without its challenges however, learning from this experience will allow the design of new placement models that will become embedded in the new curriculum. 


\section{Recommendations}

1. Comprehensive preparation for all parties

2. Robust feedback mechanisms

3. Clear documentary systems to enable consistent communication

4. Support for students who are reliant upon direction and find independent learning challenging.

\section{Key Points}

- The alternative placement was a creative opportunity to demonstrate how to meet the NMC Standards for education and training (2018)

- There are placement capacity currently underused that can provide key learning opportunities

- Practice partners and students valued the alternative placement

- Robust preparation is needed for both practice partners and students

\section{CPD reflective questions}

- Identify some alternative placements that could be used to support student learning

in your area

- What could be the benefits for student learning if the alternative placements you have identified were utilised

- What could be the challenges for practice staff if the alternative placements you have identified were utilised 


\section{References}

Ball, J., 2017 Demands on community nurse mentors: Are new models for practice

necessary? British Journal of Community Nursing. 22, 10, $504-510$.

Clarke, C., De Visser, R., Martin, M., Sadlo, G., 2014. Role Emerging placements: A useful model for occupational therapy practice education? A review of the literature. The Higher Education Academy Vol 2 , Issue 2, 14-26.

Dancza, K., Copley, J., Moran, M., 2019. Occupational therapy student learning on roleemerging placements in schools. British Journal of Occupational Therapy. Vol 82 issue 9, $567-577$

Harrison- White, King, E., 2015. Hub and spoke model for nursing student placements in the UK. Nursing Children and Young People. 27, 2, 24- 29.

Kyte, R., Frank, H., Thomas, Y., 2018. Physiotherapy students experiences of role emerging placements: A qualitative study. The International Journal of Practice Based Learning in Health and Social Care. Vol 6, no2 1-13

McClimens A., Kenyon, L., Cheung, H., 2013. Exploring placement pathways in nurse education. British Journal of Nursing 22, 1, 9- 15. 
Merrifield, N., 2015 Fifth of universities report issues with the capacity of placements.

Nursing Times. 111, 49-50: 3.

Millington, P., Hellawell, M., Graham, C., and Edwards, L., 2019, Healthcare practice placements: back to the drawing board? British Journal of Healthcare Management.

Vol25(3) P145-153

Nursing and Midwifery Council 2018 Realising Professionalism: Standards for Education and

Training - Part 2: Standards for Student Supervision and Assessment. NMC, London.

Nursing and Midwifery Council 2010 Standards for Pre-registration Nursing Education. NMC, London.

Nursing and Midwifery Council 2008 Standards for Learning and Assessing in Practice. NMC, London.

O'Leary, K., Bromley, E., 2009. Developing a mental health pathway for midwifery students. Mental Health Practice 12 (6): $527-36$.

Rylance, R., Barrett, J., Sixsmith, P., Ward, D., 2017 Student nurse mentoring: an evaluative study of the mentor's perspective. British Journal of Nursing. 26, 7, $405-409$.

Thomas, L, J., Asselin, M., 2018 Promoting resilience among nursing students in clinical education Nurse Education in Practice. 28:231-234. 
Willis, I., 2015 Raising the Bar. Shape of Caring. A Review of the Future Education and Training of Registered Nurses and Care Assistants. Health Education England, London. 